platinum was as a catalyst, supported on magnesium sulphate or asbestos, for the manufacture of sulphuric acid by the contact process; vanadium catalysts have, however, largely supplanted platinum for this purpose owing to their lower price and inertness towards impurities which poison the platinum, but platinized silica gel is still used in some contact acid plants where a high quality of acid is required and relatively pure sulphur dioxide is available.

To-day platinum and platinum alloys are extensively used for melting high-grade optical glass and for making fibre glass, for precious metal thermocouples for the measurement of high temperatures, for electrodes for making persulphates for the manufacture of hydrogen peroxide, and for spinnerets for the production of artificial fibres. The electrical industry, too, is a very large user of the platinum metals in the form of contacts of all kinds, and as resistors for electric furnaces for operating above $1,000^{\circ} \mathrm{C}$.

The catalytic properties of the platinum metals are also being exploited more extensively. Platinum and platinum-rhodium alloy gauzes are exclusively used for the manufacture of nitric acid by the ammonia oxidation process of Ostwald, and only recently it has been discovered that platinum dispersed on an alumina, silica or a silica-alumina base can be used in the vapour phase re-forming of the lighter petroleum fractions to produce high-octane motor spirit with superior anti-knock properties. Palladium, too, is finding wide applications as a hydrogenation catalyst in numerous organic syntheses. Recent American work has shown that palladium deposited on alumina is a very active catalyst for the reduction of anthraquinone to the corresponding hydroquinone, which can then be oxidized with air back to the quinone with the formation of hydrogen peroxide, a reaction first developed in Germany during the recent war for the manufacture of hydrogen peroxide for $V 2$ rockets.

Although the platinum metals, with the exception of osmium, are highly resistant to oxidation at room temperature, ruthenium, palladium, rhodium and iridium, even in the massive form, tarnish readily on heating to temperatures above $500-600^{\circ} \mathrm{C}$.; but the last three become bright again at temperatures of the order of $1,100-1,200^{\circ} \mathrm{C}$. owing to the volatilization or decomposition of the oxide ; ruthenium, however, continues to oxidize with increasing rapidity with rise in temperature owing to the formation of the highly volatile tetroxide. Platinum alone of this group remains untarnished on heating in air up to its melting point ; but nevertheless it appears to be oxidized at high temperatures in air with the formation of an unstable volatile oxide which decomposes to the metal at slightly lower temperatures; this is the cause of the bright spangles of platinum often seen on the refractory surfaces close to the platinum windings of small resistance furnaces which have been operated for long periods. That an oxidation process is the cause of this phenomenon is proved by the fact that no such volatilization occurs in a vacuum or in reducing or inert atmospheres, and if the refractory surface is kept fairly cool the platinum is deposited in a black form which contains several per cent of oxygen.

Russia and Colombia remained the chief sources of the platinum metals until about the period of the First World War, when the large increase in the output of nickel and copper from the Sudbury mines in Canada combined with improvements in the refining process resulted in large amounts of the platinum metals becoming available in the residues from the Mond process of refining nickel and, later, in the anode slimes from the electrolytic refining of the nickel and copper. The amount of the platinum metals produced from this source rapidly increased during the next decade until it reached an average of about $250,000 \mathrm{oz}$. per annum, at which figure it has remained.

In the middle 1920's large deposits of platinum ores were found in various parts of the Transvaal, principally in the Potsgietersrust, Lydenburg and Rustenburg areas, but by about 1930 only the Rustenburg area remained as an active producer. The output from this area has risen steadily until it is now about as large as that from Canada. The Merensky reef, which surrounds the Bushveld igneous complex in the centre of the Transvaal, is the principal source of the platinum metals; here they occur chiefly in combination with sulphur, arsenic and antimony in a norite rock heavily impregnated with chromite and containing nickel and copper sulphide minerals. In addition to sperrylite (platinum diarsenide), first found in the Sudbury nickel ores, and laurite (ruthenium sulphide), the South African platinum ores contain the new minerals, cooperite (platinum monosulphide), braggite (platinumpalladium-nickel sulphide) and stibiopalladinite (palladium antimonide). The platinum metals occur in these ores roughly in the proportion : platinum 100 , palladium 55 , rhodium 6 , ruthenium 13 , iridium 1 , osmium 1 .

Small alluvial deposits of platinum were discovered in Abyssinia in the late 1920's and much larger deposits in the Goodnews Bay district of Alaska in 1936. The Alaskan alluvial concentrates are remarkable in that they contain a high proportion of irid. osmine, which has an unusually high content of iridjum and a low content of osmium (only about 10 per cent). The Tasmanian alluvial deposits of osmiridium are now practically worked out; but considerable quantities of osmiridium, associated with native platinum and laurite, are recovered from the heavy black sands which collect on the corduroy tables during the treatment of the gold banket ore from various mines in the Witwatersrand area of the Transvaal; the precious metal concentrates obtained from this source contain up to 20 per cent of ruthenium with $30-40$ per cent of osmium and 25-30 per cent of iridium, but are practically free from rhodium.

\section{UNCERTAINTY, EXPECTATION AND DECISION IN BUSINESS AFFAIRS}

DURING the recent meeting of the British Association in Liverpool, Section F (Economics) held a symposium on "The Logic, Philosophy and Psychology of Business Decision-making under Uncertainty", the main focus for discussion being Prof. G. L.' S. Shackle's book, "Expectation in Economics" (second edition; Cambridge University Press, 1952). A day and a half were given to the discussion. Prof. Shackle, and many other economists, feel that the process by which a business-man reaches a decision depends very little, if at all, upon the rational assessment of probabilities which orthodox theory in the past assumed. But, of course, once 
economic theory departs from mathematical probabilities it is committed to the exploration of processes in which complexity, subtlety and even mystery are the most evident features; and yet decisions are made, and in the mass these decisions show trends and patterns which suggest that they are not altogether unamenable to rational investigation. The decisions obviously bear some relation to the facts, but they also bear a relation to the tempera. mental characteristics of the business-men who make them. Perhaps the object of the symposium might be described as that of discovering a bridge between these two very different terrains.

The present report will indicate briefly how each of the speakers at the symposium interpreted his part of the discussion. Then the treatment of a number of common themes will be described. The contributors and their topics were as follows: Prof. W. B. Gallie (University College of North Staffordshire), uncertainty as a philosophical problem; Dr. D. J. O'Connor (University College of North Staffordshire), uncertainty as a philosophical problem; Dr. I. J. Good (London), the appropriate mathematical tools for describing and measuring uncertainty; Prof. G. P. Meredith (University of Leeds), methodological considerations in the study of human anticipation; Prof. C. F. Carter (Queen's University, Belfast), theories of expectations ; Prof. B. R. Williams (University College of North Staffordshire), the impact of uncertainty analysis upon economic theory, illustrated from the theory of profit; $\mathrm{Mr}$. A. D. Roy (Sidney Sussex College, Cambridge), the possibility of empirical testing of alternative theories of uncertainty ; and Prof. G. L. S. Shackle (University of Liverpool), summing up of the discussion.

Prof. Gallie's paper was concerned with viewing Prof. Shackle's book in a perspective of scientific method, philosophy and sociology. He made the valuable point that, whereas philosophy has done much to systematize our views on moral wisdom, little or nothing has hitherto been done to systematize our accumulated prudential wisdom.

Dr. O'Connor, while accepting Shackle's concept of potential surprise, stressed the need for establishing a relation between this mental state and the objective credibility of the hypothesis under consideration. In his view the reliability of an expert judgment is "latent in the funded and assimilated experience of the expert". He opposed the assumption that there are features of human behaviour, individual and social, which are in principle unpredictable, but did not indicate how he would deal with those novel situations which form the basis of Shackle's renunciation of frequency as the factor determining credibility. This paper may be described as viewing Shackle's theory as a possible successor to the out-moded Hedonic calculus.

Dr. Good's paper was tolerant, shrewd and suggestive. It laid bare the numerous subtle and complex decisions which the mathematician must make in probability problems before he ever puts his symbols on paper, and he went behind these decisions again to the underlying theoretical and in some cases metaphysical assumptions to which the mathematician commits himself. Concerning the crucial relation between subjective degree of belief and numerical probability, Dr. Good opened out an important possibility in this remark: "The introduction of numerical probabilities does not imply that a degree of belief is always or even usually at all precise". This clearly suggests that a useful corre- lation may be established between a discontinuous series of degrees of belief and a continuous series of numerical probabilities. The paper stressed the importance of constructing axiomatic systems in this field, and indicated the diversity of practical applications of such systems.

In the next paper, Prof. Meredith discussed Shackle's function $\varphi(x, y)$ as an essentially psychological concept, and indicated the experimental problems in its empirical validation. Shackle's variables $\varphi, x$ and $y$ must be regarded as scales to be calibrated by experimental means. The variables may be discontinuous quantities, in which case Shackle's use of the differential calculus would be inappropriate. There may be several qualitatively different varieties of probability, and a probability may in many cases not be capable in principle of being expressed by a single number, but rather by a pattern of propositions, "the pattern of evidence of rational likelihood". Prof. Meredith's paper was illustrated by a model constructed to facilitate the discussion of Shackle's $\varphi$ function (see Fig. 1). In this model $x$ represents values of the various possible outcomes of a business venture $(z=-x$ represents losses). $y$ represents the 'degree of belief, measured inversely as potential surprise' which the individual attaches to the various outcomes. $\varphi$, orthogonal to the $x, y$ plane, represents the mental stimulus or 'interest' afforded by the various pairs of $x, y$ values. At 0 , and for a certain 'inner range', zero surprise is attached to small gains and losses. Maximum surprise, or 'impossibility', $\bar{y}$, is attached to very high gains and losses. The basin-shaped curve represents the impact of the business venture on the mind of the enterpriser and reaches maximum $\varphi$-values at two points-the 'focus-outcomes', representing maximum stimulus and deterrence, and determining the decision made; these are, in general, at intermediate values of $x$ and $y$. The contours of the surface are characteristic of the individual's temperament. The continuous surface of this model implies continuous variables.

Prof. Carter explored the implication of discarding the continuous variables in Shackle's theory, and replacing them by discontinuous steps. Numerical measures must then be replaced by rankings. This raises a fundamental difficulty for Shackle's model, since "It is a logical impossibility to devise a means of compounding two pure rankings (or one ranking and a numerical index) to make another unique ranking". Prof. Carter demonstrated by a series of examples the novel kind of reasoning to which such an assumption would commit us.

Prof. Williams cast his net both wide and deep in the fundamentals of economic theory. He contrasted static theory with its assumption of equilibrium conditions as a basis for rational decisions at the price of unreality, with dynamic theory with its implications of change and uncertainty, and its need for theories of probability. The economist's habit of making psychological assumptions carries with it the need for consulting psychologists and sociologists. He welcomed Shackle's theory as an attempt to provide a new conceptual framework of "expectational dynamics". The rest of the paper was an inevitably somewhat technical discussion of the impact of expectational dynamics upon Keynesian theory with particular reference to profit. Prof. Williams closed with a plea for a sociological analysis of the goals of business firms and organizations within the socio-political system. 

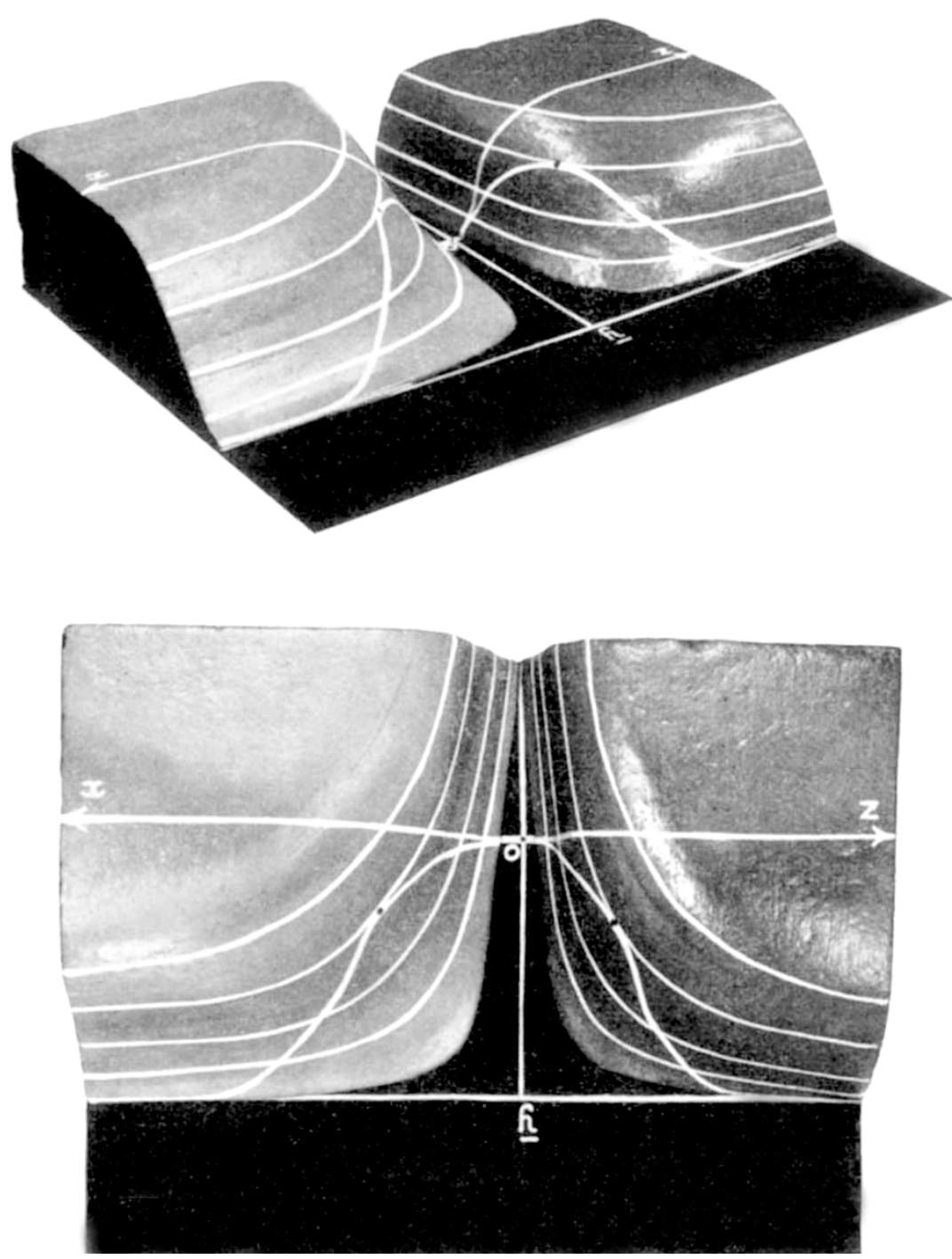

Fig. 1. Model of the Shackle function $\varphi(x, y)$

Prof. G. L. S. Shackle surveyed the discussion, and has prepared the following statement relating to his comments : If we understood how decisions are made, we should understand how history is made. So far as this is true, it is rather obvious. Yet decision-making, the focal creative psychic event where knowledge, thought, feeling and imagination are fused into action, seems to have received only the most casual glances of scientific men and other scholars. Mathematics has shown in probability theory how to derive knowledge concerning aggregates of future events from aggregates of past events, but this technique is irrelevant to personally unique and crucial occasions of decision by an individual. Frequency. ratios are knowledge and have nothing to do with uncertainty. The individual can choose only between imagined and not between realized experiences, for when an experience is actually proceeding it is too late to choose something else. Thus decision must, it seems, be guided or determined by the thrust of imagined and anticipated enjoyments and distresses.

The relevant, legitimate and useful question for a person to ask himself, when his decision on this course of action, rather than that, will swing the

Mr. Roy attempted in his paper to specify actual methods by which different theories of uncertainty might be empirically tested. The link between past events and future outcomes is too tenuous and varied. to allow of the elimination of what methodologists call the "intervening variables" of motive and expectation, but how can different theories of expectation be tested? The first suggestion would be a statistical analysis of economic time series. The second would be by laboratory experiments on individuals placed in situations which mimicked as far as possible those confronting the typical businessman. Neither of these is promising. Mr. Roy recommended the compilation of individual case-studies of decision-takers in action by a research worker living in constant daily touch with the business-man, and having access to all the necessary information and business text-books to throw light on the latter's decisions. Mr. Roy indicated the methodological difficulties in the use of such data for discriminating between alternative theories of uncertainty. whole evolution of his affairs into a different path, is not: How can I add together all the rival, mutually exclusive hypothetical outcomes of this course of action? for the result of such addition would be meaningless; and the question is not: What will be the result of this course of action? for that cannot be known. The question is : What is the most exciting result that I can imagine this course of action as capable of producing, and again, what is the most alarming result ?; where excitement and alarm each depend on two matters, the face-value of any hypothetical outcome in question, and its plausibility; and if we are to consider a hypothesis by itself, the measure of plausibility must be something radically and essentially different from numerical probability, which depends for its meaning and existence on the viewing of hypotheses in their gregarious collectivity. By a line of thought which is too long to reproduce here, I have been led to invert the problem and adopt a measure of disbelief instead of a measure of 
positive confidence. The consequences are farreaching.

If the line of ideas, the general direction only of which I have space to indicate, is to lead beyond a mere theoretical construction and make a solid contribution to knowledge, the interest and effort of philosophers, logicians, mathematicians, psychologists and economists will be needed for the intensive exploration of a territory the outlines of which were so brilliantly mapped by the seven contributors to the symposium at Liverpool.

So much for the distinctive features of the individual contributions. The following concepts and themes recurred in a number of the papers, and these suggest the movement of thought from which new developments in expectation theory may emerge.

Dissatisfaction with the frequency theory of probability. Decisions have often to be made concerning novel and unrepeated ventures. To these any frequency measure of probability is inapplicable; but even where it is theoretically applicable, there is a growing disbelief in the facile assumption that business decisions are based upon it.

The realization of the need for greater psychological realism on the part of economists. In a world in which the irrationality of man is everywhere manifest, it does seem somewhat naive to assume that the business-man, of all people, is gifted with some unique degree of rationality which would give a mathematical sanction to his daily business decisions. It should, however, be pointed out that the word 'rational' itself demands some scrutiny. It is used to mean either 'effective' or 'ratiocinative'. There is a sort of practical rationality, or expertize, which depends upon years of experience rather than upon ratiocination. It is this which gives some measure of cogency to the degree of belief which the expert accords to the particular proposition.

The magnitude of the methodological problem. This is multifarious, and includes the relations between the social and the individual, conception and action, continuity and discontinuity, single and multiple causation, and a host of other relations.

The bearing of causative contexts and conceptual frameworks. The isolated business decision is probably a fiction. Decision arises out of the conceptual framework of the individual, and takes place within his socio-economic context.

The role of the conceptual model in theory-making. Theory attempts to simplify and clarify the welter of facts. It can do this only by setting up relatively self-contained abstract models; such a model, if it is to survive, must possess three features : internal consistency, as determined by logical analysis; validity, as determined by empirical tests; and power, as determined by its utility in both clarification and prediction.

The problem of quantification. This is an aspect of the validity problem, for in comparing empirical data with predicted outcomes there is a direct comparison of quantities. The theory of measurement is far from complete; even the physicists have their problems of metrology. Psychometrics and econometrics present problems of even greater complexity, but these are a challenge rather than a ground for pessimism.

A growing need for an adequate calculus of discrete quantities (as against the calculus of the arithmetical continuum). This may not be difficult for the pure mathematicians, but the users of mathematics would need to acquire new habits of thought, as well as new modes of calculation. The landscape model of Shackle's function in the accompanying illustration would have to make way for a model of steps and movable platforms.

G. P. Meredith

\section{PROTON SYNCHROTRON OF THE UNIVERSITY OF BIRMINGHAM}

$T$

HE proton synchrotron in the Physics Department of the University of Birmingham is now able to accelerate particles to an energy of $1,000 \mathrm{MeV}$.; it first operated at full energy on July 16. A greater energy than this is known to have been reached artificially only in the United States, where the Brookhaven 'Cosmotron' ${ }^{1}$ gives protons of an energy of $2,300 \mathrm{MeV}$. These two machines, together with a rather larger proton synchrotron approaching completion at Berkeley, California, are designed to provide experimental facilities for nuclear physics in an energy range above that which is economic for synchro-cyclotrons. Future proton synchrotrons, planned to incorporate the new strong focusing principle, will probably extend the energy scale considerably further.

The Birmingham synchrotron has been developed from the original proposals of Oliphant, Gooden and $\mathrm{Hide}^{2}$, whose aim to reach a proton energy of about $1,000 \mathrm{MeV}$. was, just after the Second World War, ambitious but not unreasonable. Detailed design began in 1946 with the aid of a grant from the Nuffield Foundation, and construction started in 1947. The project was under the guidance of Prof M. L. Oliphant until he left the laboratory in 1950 , and, since then, responsibility for the development and testing of the machine has been in the hands of the present head of the Department, Prof. P. B. Moon. The undertaking has been financed mainly by the Department of Scientific and Industrial Research, without the support of which the project could scarcely have been undertaken by a university department. Several large and important parts of the equipment, such as the motor-generator, vacuum sections and high-tension generator, were supplied by outside firms; but the main technical responsibility has been undertaken throughout by the Department of Physics, and much of the actual construction was provided by the departmental workshops. The very considerable technical effort necessary has been supplied over six years by a large number of physicists and assistants, many of whom are no longer in the laboratory to witness the successful outcome of their work.

The first notable feature of the Birmingham synchrotron is its size. This is not shown to advantage in the accompanying photograph, since the machine had to be built within the fairly small space available in the Nuffield Research Laboratory, which was designed for (and still houses) the University 60-in. cyclotron ${ }^{3}$. The illustration gives a general view of the magnet (810 tons), which is built of C-shaped steel laminations $\frac{1}{2}$ in. thick, arranged in a circle with the annular gap outwards. The diameter of the mean horizontal orbit in which the protons circulate is $900 \mathrm{~cm}$., and the magnetic field necessary to keep a proton of an energy of 1,000 $\mathrm{MeV}$. moving in an orbit of this size is 12,500 gauss. Power for the magnet is supplied by a motor-generator set developing 